\title{
Teleological pitfalls in reading evolutionary trees and ways to avoid them
}

\author{
Thilo Schramm ${ }^{*}$ (D) and Philipp Schmiemann (0)
}

\begin{abstract}
Despite evolution being the central idea in modern biology, considerable variation exists in its acceptance around the globe, and reports of anti-evolutionist and creationist movements are widespread. Educators need to re-evaluate the approaches used for teaching students about evolution in order to facilitate its understanding and acceptance. A major hurdle in understanding the concepts of evolution is that humans tend to view the world in a teleological way. Learners create obstacles to understanding the concepts of evolution by ascribing purpose or intent-driven actions to animals, processes, or inanimate objects. An indispensable learning tool in the field of evolution is the evolutionary tree, as it is a direct representation of evolutionary hypotheses. The ability to read and understand this form of representation is prerequisite to fully understanding the concepts of evolution. In this work, we present issues faced when attempting to teach students to read evolutionary trees as well as troublesome diagrammatic properties that may foster teleological thinking. Further, we present teaching practices and methods that may be used to avoid the above challenges (from diagrammatic and instructional perspectives). With this work, we aim to raise awareness among educators about the different potential teleological pitfalls in the field of teaching how to read evolutionary trees, and to present different approaches for minimizing teleological reasoning and thinking in evolution education.
\end{abstract}

Keywords: Evolutionary theory, Teleology, Phylogenetic tree, Learning process

\section{Background}

In modern biology, evolution and evolutionary analyses play an increasingly important role (Futuyma 2013; Taylor et al. 2018), further corroborating Dobzhansky's claim that evolution is biology's unifying principle (Dobzhansky 1973; Futuyma 2013; Kelemen 2012). However, students at all educational levels struggle to grasp the central concepts of evolutionary biology, which hinders their understanding of biology in general (Abrams and Southerland 2001; Ariew 2003; Cunningham and Wescott 2009; Gregory and Ellis 2009; Kattmann 2008; Werth 2012). As evolutionary trees are the most direct representation of macro-evolutionary processes and are used as hypotheses concerning the relative relatedness of species, they are an indispensable tool in the learning and communication about evolution (Baum et al. 2005; Meisel 2010; Nehm and Kampourakis 2014). The concepts

*Correspondence: Thilo.Schramm@uni-due.de

Biology Education, University of Duisburg-Essen, Universitätsstraße 5, 45141 Essen, Germany of reading and interpreting evolutionary trees are poorly understood by students of biology, similar to how they find it difficult to understand evolution (Baum et al. 2005; Gregory 2008; Kummer et al. 2016; Omland et al. 2008).

The theory of evolution is known to spark controversies globally, regardless of country or culture. The acceptance of the theory of evolution in a population varies between different countries, with some countries showing a high percentage of acceptance ( $80 \%$ in France, $75 \%$ in New Zealand) to some countries showing lower percentages of acceptance (54\% in Missouri, US; $17 \%$ in Malaysia) (Campbell 2018; Friedrichsen et al. 2018; Lay et al. 2018; Quessada and Clément 2018). In addition, the share of the population holding creationist beliefs also varies between the states and regions. It has been reported that the acceptance of creationism and intelligent design is on the rise in different countries (Reiss 2018). The level of acceptance of the theory of evolution and its wide range is attributed to different factors, including religious views, cultural traditions, geographical diversity, and individual proficiency (Borgerding and 
Deniz 2018; Deniz and Borgerding 2018). Accepting evolution and understanding its concepts are closely linked. However, the tendency to think teleologically hinders student understanding of the theory of evolution (Barnes et al. 2017; González Galli and Meinardi 2011).

In this work, we aim to present theoretical considerations about the teleological pitfalls in teaching how to read evolutionary trees, based on data from earlier studies. These pitfalls will be structured into three parts: two major cognitive hurdles-the great chain-of-being and the complexity idea-and troublesome diagrammatic properties of evolutionary trees. In addition, we present different approaches to overcome these pitfalls.

\section{Teleology}

The concepts and processes of evolutionary biology seem to be poorly understood by high-school students, members of the public, and even post-secondary students and graduates of biology (Gregory 2009; Nehm and Schonfeld $2007,2008)$. One of the fundamental difficulties in learning evolutionary biology is that human beings tend to see the world from a purpose-driven and goal-oriented perspective (Gregory 2009; Kelemen and Rosset 2009). This might be because we expect other living beings, processes, and inanimate objects to behave as humans would, with planned and purposeful actions (Mead and Scott 2010a, b). Thus, it is not surprising that not only novice learners but also other humans tend to see evolution as a purposeful and directed process (Catley et al. 2010; Kampourakis 2014; Kelemen 2012).

Teleological thinking is a way of thinking wherein objects or processes behave with the underlying intention to fulfill their specific goal (Kelemen 1999a; Rosenberg and McShea 2008). This notion is specifically strong in children; however, it persists through their high school and university years (Gregory 2009; Kelemen and Rosset 2009; Southerland et al. 2001; Trommler et al. 2018). Furthermore, in teleological explanations, inanimate objects or parts of living beings (such as organs) are often falsely attributed with consciousness and goal-directed actions (Tamir and Zohar 1991).

The teleological bias occurs in students during their preschool years when trying to understand many aspects of the natural world. Children at this age typically view the existence of organismal traits as serving the physical good of the organism, while viewing artifacts' properties as existing for the benefit of external agents (Keil 2002; Kelemen 1999a). Further, preschool and elementary school children ascribe both living organisms and artifacts as being "made for something" (Kelemen 1999b, c). While young adolescents can grasp the complex concept of evolution-that animals can change substantially over a period of time-they tend to have a teleological bias because of the explanation that animals change with the purpose to adapt (Evans 2001). During their secondary schooling, students often argue teleologically about the existence of traits in animals. For example, they explain that canines need structures such as claws and teeth to catch their prey (Kampourakis and Zogza 2007).

A major reason for teleological reasoning in biology is the general tendency of humans to think in a goaldirected manner. As our everyday lives involve overcoming difficulties, completing tasks, and fulfilling needs, we are inclined to regard many situations with a goal-oriented perspective, and therefore, we exhibit a teleological bias to the purpose or function of objects or processes (Gregory 2009).

\section{Teleology and evolution}

Teleological thinking can emerge in different forms in the context of evolution. One example is that evolutionary processes are seen based on the following three ideas (González Galli and Meinardi 2011): (1) The process of evolution aims to create certain lineages or species (especially humans). (2) The process of evolution aims at securing the survival of species. (3) Individual variations arise to fulfill needs forced upon species by the environment and to overcome survival challenges. Another way that teleological thinking can become apparent is when learners answer evolutionary questions containing the word "why" with responses that are more reflective of the questions "For what purpose?" or "What is it for?" instead of the scientifically accurate sense of "What is the cause?" (Kelemen 1999a). These interpretations can imply that students assume biological processes to follow a function instead of being the result of a complex set of influencing factors.

Different beliefs and concepts in evolution that can form hard to overcome misconceptions are based on teleological ideas (Kampourakis 2014). As some students see evolutionary change as a means of overcoming survival challenges, they assume that evolution is a development of increasing complexity. By purposefully overcoming challenges, species become more complex and are therefore "more (highly) developed" than other species. Therefore, the notion of seeing the taxonomic system as an increasing order of complexity could be a consequence of teleological thinking as proposed by Kummer et al. (2016). In the course of this work, we will lay out this idea in more detail.

\section{Evolutionary trees as representation of evolution}

An important element in learning and communicating about biology is graphical representation (Wiley et al. 2017). In the case of evolutionary biology, phylogenetic, or evolutionary trees are an indispensable tool for 
communication (Baum and Smith 2013). Evolutionary trees are diagrammatic hypotheses about relative relationships among taxa and are seen as the most direct form of representation of macro-evolutionary processes (Baum et al. 2005). They not only show the results of evolution by displaying the relative relationships of selected species, but also act as a tool to investigate evolutionary processes (Baum and Smith 2013). Therefore, the ability to work with evolutionary trees is seen as prerequisite to fully understanding the concepts and processes of evolutionary biology (Catley et al. 2012; Meisel 2010).

The aspects of reading, interpreting, and utilizing evolutionary trees are subsumed under the term "tree-reading", which, along with aspects of creating a hypothesis for an evolutionary tree from given data, is called treethinking (Baum and Smith 2013; Halverson 2011). In this paper, we will focus on the aspect of tree-reading. The ability of reading evolutionary trees consists of a number of different skills, ranging from the knowledge of diagrammatic elements, such as internal nodes, over-reading and interpreting new traits (apomorphies), evaluating relative relationships of species, and forming monophyletic groups to compare and contrast different evolutionary trees (Halverson 2011; Novick and Catley 2016; Schramm et al. 2019).

Despite the relevance of tree-thinking, numerous studies show that students struggle with these kinds of representations and that working with evolutionary trees is an issue at all educational levels (Baum et al. 2005; Blacquiere and Hoese 2016; Bokor et al. 2014; Kummer et al. 2016; Meir et al. 2007). This can be explained, as numerous known factors can affect the difficulty of reading evolutionary trees. Reading evolutionary tree diagrams is a complex task and is influenced by factors such as knowledge of evolutionary concepts (MacDonald and Wiley 2012) and prior knowledge about the morphology of species (Novick and Catley 2014). Besides studentrelated factors, factors on the side of the diagram can affect the reading difficulty of a tree (e.g., Catley et al. 2012; MacDonald and Wiley 2012; Novick et al. 2010). Furthermore, numerous persistent and widespread misconceptions have been reported, such as the idea that straight, uninterrupted lines represent no evolutionary change, or that the order of presented species represents their relative relationship (as opposed to the branching pattern) (e.g., Gregory 2008; Meisel 2010).

As teleological thinking is seen as one of the major hurdles in teaching evolutionary biology (Barnes et al. 2017; González Galli and Meinardi 2011), educators and researchers attempted to examine what leads students to adopt or discard teleological reasoning and how to teach evolutionary biology in the best manner so as to foster scientific interpretations of evolutionary concepts.
Just as teleological thinking is seen as a central issue in learning about evolutionary biology, the ability to read evolutionary trees is seen as a crucial prerequisite in order to fully understand the theory of evolution. In addition, tree-reading is seen as a major skill in modern evolutionary biology, but studies show that students at all educational levels show major deficits in these skills (Catley et al. 2012; Gregory 2008; Kummer et al. 2016; Omland 2014). In this work, we want to examine the results of ongoing research and theoretical considerations on tree-reading with the focus on identifying and presenting typical teleological pitfalls in teaching as a part of evolutionary biology. Subsequently, we want to present ideas about how evolutionary trees can be used in a constructive way in order to teach tree-reading scientifically and inspire activities that can help students appropriately deploy teleological reasoning.

\section{Teleological pitfalls}

Teleological reasoning is seen as a central hindrance in learning about evolutionary concepts, and therefore, we want to present different misconceptions and settings in practice where teleology might interfere with teaching tree-reading. In this section, we present the two overarching misconceptions of evolutionary biology, the chain of being and the complexity idea, and we explain how these ideas can reveal themselves in the context of evolutionary trees and the ways in which they might be unintentionally reinforced by teaching practices. In the second part of the section, we focus on the properties of evolutionary tree diagrams, which can facilitate teleological interpretations.

\section{Pitfalls in evolutionary trees Chain of being}

Before Darwin's revolutionizing work on the evolution of species (1859), (natural) philosophers tried to structure the diversity of life. These earliest concepts of natural systems usually followed the idea of the "Great Chain of Being" or "Scala Naturae" with a vertical representation of the system of species. At the lower part, "simpler" species are depicted; following the order up, the complexity of presented organisms increases, typically climaxing with humans or God at the top of the natural order (Gregory 2008; Matuk 2007). In the historical context, these representations were based on the idea that life was created by a divine being in an event of full creation. Therefore, all of the different forms of life were seen as having the same age and as not changing over time (Matuk 2007; Mogie 2000). This form of presentation is highly questionable from a modern perspective as it implies the problematic concept that evolutionary development culminates in a small number of advanced 
species and thus, it is a teleological perspective (Catley et al. 2012). Furthermore, it implies that different species are more or less evolved or complex. Today, no scientifically justifiable basis can be applied to rank species with regards to their complexity or their "rank" in the natural system (e.g., Gould 1996). Nevertheless, the general idea of the Chain of Being is not only present today, but is actually a frequently reported and widespread misconception (Gregory 2008; Kummer et al. 2016; Nee 2005; Philips et al. 2011).

A more recent description of thinking in line with the Chain of Being is what has been termed "developmental thinking" (O'Hara 1997), where evolution is seen as stories of individual development while investigating the developmental history of one species from a root to the present without taking into account the branching nature of lineages.

Considering evolutionary processes and concepts, representations in the linear style of the chain of being (or developmental thinking) do not show relevant concepts such as: the splitting of populations leading to speciation, extinctions, the relative relationships of different species, new evolutionary traits (apomorphies), or any other indicators of a modern understanding of evolution.

\section{Pop-cultural influence on teleological reasoning}

Probably the most prominent iconographic depiction of the concept of evolution in popular culture follows the idea of the chain of being. The typical form of this well-known iconography (see Fig. 1) shows a linear progression from left to right in varying compositions. Sometimes starting from unicellular life, with different steps leading to modern humans on the left, but most prominently, from a crooked ape on the left, to an upright human on the right (Baum and Smith 2013; Clark 2009; Gould 1995).

This kind of iconography can convey different ideas not supporting the concepts of evolution. The direct line from a "simple" or "primitive" ape to the upright, developed human could imply that evolutionary processes strive to increase the complexity of living beings and that humans are the pinnacle of the living world. This notion could be further supported by the typical increase in heights of the presented organisms from left to right. Furthermore, one could interpret this image to support the idea that humans developed from apes but are not apes themselves. Thus, this kind of image represents the idea of the chain of being as a valid depiction of evolutionary processes and thus fosters teleological thinking (Werth 2012).

\section{Complexity idea}

As biologists explored the diversity of life and tried to organize living things into different groups, they expanded the concept of the chain of being. Instead of a linear progression of complexity, branching depictions were used, often in the form of actual tree-like pictures. In these early organizational works, classification was mainly based on morphological structures and different groups were typically seen as more or less "primitive" or "complex." In these tree-like-depictions, "lesser" groups were presented closer to the stem of the tree, whereas "highly complex" organisms or groups, including men, were presented on the branches at the top of the tree (Matuk 2007; Mogie 2000). Evolutionary trees in this form of the tree of life are still used in educational literature and only in a minority of the cases are these diagrams put in an appropriate historical context (Catley and Novick 2008).
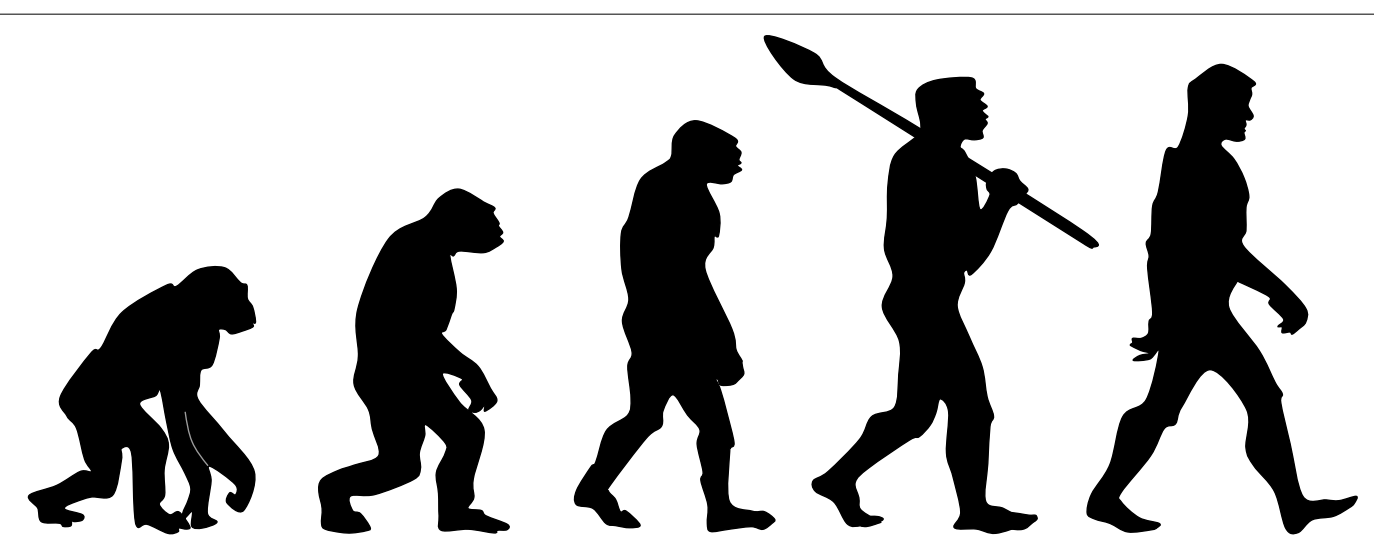

Fig. 1 Pop-cultural representation of the human evolution. This stylized representation is typical for popular-cultural of -scientific depictions of human evolution. It does not show any bifurcation events, extinction of species and thus can evoke the idea, that evolution is a directed process, leading to modern humans as the pinnacle of life 
The idea that different species are more or less evolved, or the notion of "higher" or "lower" species is problematic as it nourishes the idea that evolution pursues a rise in complexity over the course of time as a type of purpose, thus being deeply teleological (Kummer et al. 2016). In the context of tree-reading, it can be seen as the most problematic form of teleological interpretations, as multiple common misconceptions in reading evolutionary trees are heavily based on this idea (Baum et al. 2005; Dees et al. 2014; Gregory 2008; Mogie 2000; Omland et al. 2008). In the following text, we will call this concept the "complexity idea".

The complexity idea can be an indication of teleological thinking in evolution, as it backs the concept that evolutionary processes are "aimed" at inevitably bringing up more complex forms resulting in modern humans (Mogie 2000). As it is the core of many different (teleological) misconceptions, with regards to evolution in general and depictions of evolutionary processes in specific, we lay out different factors promoting the complexity idea in the context of evolutionary biology below.

\section{Reading across the tips}

A common misconception in reading evolutionary trees based on the complexity idea is called "reading across the tips" (Gregory 2008). It describes the concept that students tend to ignore the branching pattern of a given tree and rather read the presented organisms in the order they are presented, as a direct line of rising complexity, depending on the orientation of the tree, from left to right or from bottom up (Blacquiere and Hoese 2016; Gregory 2008; Kummer et al. 2016). This leads to students largely ignoring the branching pattern of the tree and thus drawing wrong inferences about the information presented. As the organisms are seen as being arranged in a continuum of rising complexity, this misconception reveals the notion that species can be arranged according to their "higher" or "lower" development.

\section{Order of teaching evolution}

The complexity idea might be unintentionally supported by many scientists and educators by the way they present information. Multiple books about evolution, some by well-known scientists, are structured in support of the idea of increasing complexity by following an arrangement similar to the Chain of Being (Nee 2005). Often, they begin with describing the origin of life and the first living organisms and continue with events like the first eukaryotic cell, multicellularity, leaving the water, first mammals, and in the end, human beings. This common order of how to present evolutionary history is suited to nourish the idea that evolution works on increasing the complexity of life and that humans are the pinnacle of biological life (Nee 2005). By sustaining the notion that evolution is a process producing beings that are ever more complex and that one can follow a "complexity ladder" through the domains of life, the interpretation of evolution being a process with the purpose to spawn ever more complex beings might be enticing. Teaching this way could support the complexity idea and associated teleological views about evolution.

\section{Teleological wording}

The way an educator chooses his or her wording can have a considerable influence on the way students understand a topic. This is especially true in the case of evolutionary biology, as many professional biologists and educational textbooks regularly use teleological formulations, despite not intending to teach teleological interpretations (González Galli and Meinardi 2011; Hanke 2004; Ruse 2009; Werth 2012). For example, one could say that the heart evolved to pump blood, and the underlying meaning of this statement is that the heart underwent an evolutionary process, adapting and shaping it, which resulted in a better-adapted morphological structure. The statement is not meant in a way that the heart was originally designed as a blood-pump. Another example is the statement that a species lives in flocks to defend against predators. Here, the reason of living in flocks is an evolutionary adaptation and not the idea of an individual organism that living in a group could be a good way to repel predators. Typically, educators assume that their students understand their teleological formulations as metaphors and do not want to foster teleological reasoning. This raises the risk that students might become used to teleological wording and adopt it without regarding the metaphorical nature or might directly adopt teleological reasoning (Kelemen 2012; Werth 2012). Furthermore, textbooks often focus on the functions of biological systems or processes without shedding much light on the causes. This can lead to students analyzing biological concepts from a teleological perspective (Abrams and Southerland 2001). The issue of teleological wording is not only present in educational textbooks or oral presentations, but also in peer-reviewed publications, especially with the use of the classification into "higher" and "lower" species, and therefore, in the form of the complexity idea.

\section{Effects of representational elements and styles}

Darwin's publication of the concept of evolution as descent with modification introduced trees representing the order of life: Lines did not represent some similarity between different groups any more, but a direct relationship by descent. These diagrams came in various different forms, and conventions on how to best 
present evolutionary relatedness had yet to be found (Pietsch 2012). In modern phylogenetics, three forms of evolutionary tree diagrams are most prevalent: rectangular trees (also called tree diagrams), diagonal trees (also called ladder diagrams or trees), and circular trees (Fig. 2), although the latter are rather scarcely used (Catley and Novick 2008; MacDonald and Wiley 2012). Different representational styles can lead to different interpretations of a given tree, especially with novice learners (Catley et al. 2012), although all styles carry the same informational value. Furthermore, the absence or presence of certain elements of a tree can change the difficulty of reading the tree or influence the way it is read. In the following, we will present different aspects of the representational style of evolutionary trees that can foster teleological ideas while working with them.

\section{Diagonal trees}

Diagonal trees can especially support misconceptions in reading evolutionary trees. For example, students tend to interpret diagonal trees by seeing long lines as an entity, determined by its terminal taxon (see taxon $\mathrm{A}$ or $\mathrm{F}$ in Tree b in Fig. 2). This interpretation leads to interpreting branching events as other groups developing "away from the main branch," and thus, implying the idea of a main line of development, usually culminating in humans, with different other, inferior developmental lines (Gregory 2008; Halverson and Friedrichsen 2013; Omland 2014). This interpretation is especially prominent as students follow the Gestalt principle of good continuation. Depending on which species are presented at the end of one long, continuous line, the representation can support teleological interpretations. For example, if humans are presented at the end of the uninterrupted long line at one side of the tree, it could be seen as a directed evolutionary

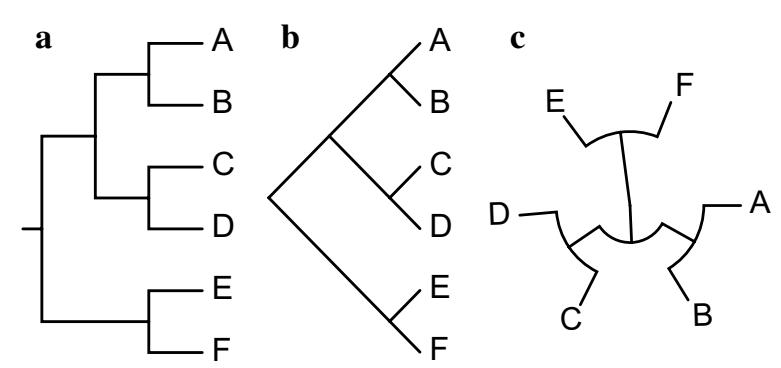

Fig. 2 Most widely used tree formats: a rectangular tree/tree diagram, $\mathbf{b}$ diagonal tree/ladder diagram, and $\mathbf{c}$ circular tree. Although the three formats look differently, they show the same branching pattern and therefore convey the same information. Nevertheless, the difficulty in reading them varies, as they are susceptible to different misconceptions process culminating in the development of humans, with other taxa as mere side branches of this development.

\section{Anagenetic diagrams}

Anagenetic diagrams are largely used when representing the evolutionary history of modern humans and in the case of the evolutionary history of the horse (Catley and Novick 2008). These diagrams typically put different species into perspective based on the fossil record, and at least two different species are linked directly and successively along a single branch of the tree without a bifurcation event (Catley and Novick 2008). This form of presentation can easily be interpreted as the representation of anagenetic processes, one species turning into another, without a branching event occurring (Philips et al. 2011). The idea that evolutionary processes are transformation processes, turning one species into another, is seen as being linked to the teleological interpretation of the presented data (Novick et al. 2014; Philips et al. 2011; Scott 2010). Here again, we can find the complexity idea, as one species seems to develop into a new and "higher developed" species, leading to extant species we know today (Novick et al. 2014).

\section{Orientation of the tree}

Besides the style of the tree, the orientation of the trees can have an influence on the way learners interpret the presented information. If extant species in a tree are presented along a vertical axis (so the flow of time is presented horizontally), novice learners tend to interpret the tree in a teleological way by ascribing species at the top to be highly developed. The interpretation with the tree rotated and extant species presented along a horizontal line is less common (Philips et al. 2011).

\section{Lines represent no change}

Many learners possess the misconception that lines in an evolutionary tree represent no alterations and only nodes represent evolutionary changes; therefore, this can be seen as a concept similar to the idea of main branches, described in the context of diagonal trees discussed above. The concept that lines represent no change can be interpreted as teleological fallacy, as it can imply that evolutionary changes occur for the reason of speciation (Kummer et al. 2016). A consequence of this idea can be the well reported misconception that students attempt to evaluate relative relations of species by counting nodes along the lines between different species (Gregory 2008; Meir et al. 2007).

\section{Unbalanced trees}

The number and arrangement of taxa in a given tree can have a major influence on the way learners read a tree. 
When presented with a tree where different clades or parts of the tree feature very unequal numbers of presented species, students tend to interpret the clade with less groups as a more primitive one (Gregory 2008; Meisel 2010). Just as the general idea of different species being differently "developed" or more or less primitive is not supported by evolutionary reasoning, this concept is also flawed. As every evolutionary tree shows a selection of species or groups, typically any branch can be provided with a number of additional branching events to tip the proportion of the number of presented species in the interpreted clades.

\section{Age of groups}

A form of evaluating relative relationships in a tree that is tightly linked to the complexity idea is the notion that different extant groups in a tree are older or younger; this implies that the older group is less evolved or more basal than the younger group. The idea of this concept is that different taxonomic groups emerged at different times throughout the history of the earth; for example, the first organisms later classified as birds lived before the first organisms later classified as humans (see Fig. 3). Novices in reading evolutionary trees tend to attribute groups with early branching events as being less evolved because of the time of divergence in a presented tree (Gregory 2008).

In a given tree, all extant species are the same age. The time from the root of the tree to the tips is the same for all presented species (extinct species not factored in), and therefore, their total time of evolution is the same (Baum and Smith 2013). As trees presented in publications can only show parts of the complete evolutionary tree of all living beings, the number of branching events along a given lineage cannot be interpreted meaningfully. If a tree is presented with a scaled time axis, branching events on different lineages can be set into relations by stating that one branching event occurred before the

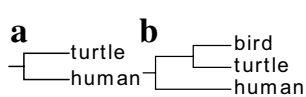

Fig. 3 Interpretation of the age of groups based on branching pattern. In these two trees, all species evolved the same time. In tree (a) both the turtle and man obviously seem of the same age, as they share a root and simply diverge at one point. In tree (b) the sister group of humans has been expanded by the group of birds. A common misconception is to call human an older group or earlier branching group in tree $\mathbf{b}$. Of course, this is not applicable, as the bird-turtle and human branches diverge at the same time, and the bird-turtle branch simply diverges at an additional time. In most cases, the interpretations of earlier branching are interpretations focused on the number of branching events in different lineages other. Nevertheless, this does not justify any interpretation of less or more advanced clades in a tree (Baum and Smith 2013; Mogie 2000), which could be the basis for teleological interpretations, following the complexity idea.

\section{Interpreting focal taxa}

The positioning of humans in evolutionary trees is a common feature in teaching tree-reading (Sandvik 2009). Presenting humans (or the taxonomic group containing humans, like mammals or vertebrates) in a tree in a position at the outer side of the branching pattern can support interpretations of the species being presented in an ascending order of complexity (complexity idea). Such a prominent position can also corroborate anthropocentric tendencies and the interpretation that evolutionary processes culminated in modern humans (Sandvik 2009; Philips et al. 2011). Both interpretations can be seen as a feature of teleological reasoning (Meisel 2010; O'Hara 1997; Philips et al. 2011). Often, humans are presented in a prominent position in evolutionary trees, at the edge of the diagram, depending upon the general orientation at the far right or the top of the tree. By positioning humans at the edge of the tree diagram, their position implicitly places focus on them, implying that humans deserve focus or are a type of endpoint. Interpreting a tree this way can lead to the conclusion that evolutionary processes took place in order to lead to humans as a special group of organisms, in an extreme form, to humans as the pinnacle of life on earth (Meisel 2010; Philips et al. 2011; Sandvik 2009). The same principles hold true if the tree shows another focal taxon instead of humans.

\section{Different levels}

Another factor influencing the perception of different species as "higher" or "lower," is whether extant species in an evolutionary tree are presented at the same level in the diagram. In a cladogram, the length of the branches has no informational value, and therefore, all extant species are typically arranged on a line orthogonal to the direction of the flow of time and only extinct species are presented at lines ending earlier (Catley and Novick 2008). In special trees such as phylograms or chronograms, the length of the branches represent evolutionary changes, mutation rates, or time. However, in modern educational literature, extant species are frequently presented in diagrams on the same level without the branch length showing any metric logic (Catley and Novick 2008). Diverting from the design that extant species are presented at one level can lead to students interpreting the tree in a way that different species are seen as being less evolved or more primitive, which could lead to teleological interpretations of the tree. If the species are presented at different 
levels on purpose, the design should be clearly highlighted and explained in the diagram.

Evolutionary trees are a highly context-specific form of representation in evolutionary biology, and unfortunately, numerous teleological pitfalls exist in constructing or presenting them in a learning context. In a modern learning context, we can still find interpretations and concepts based on scientific interpretations that are many centuries old. In fact, one of the most fundamental hurdles in reading evolutionary trees is that learners tend to attribute different complexities to presented organisms and see them as more or less developed. In an extreme form, learners think of a linear order for the complexity of species and use this as a basis for evolutionary explanations. This hurdle-the complexity idea-can be corroborated in the context of evolutionary trees by different teaching practices and diagrammatic properties. Furthermore, an evolutionary tree is comprised of numerous elements, whose absence or presence can influence teleological interpretations.

\section{Avoiding the pitfalls}

As discussed previously, numerous misconceptions and practices can potentially foster teleological thinking in the context of evolutionary trees. In the following section, we present different ways to avoid or at least reduce the challenges caused by some of the described obstacles. The practices presented here can be divided into two main groups: practices with the perspective of choosing or modifying suitable diagrams and practices with the perspective on teaching strategies while working with evolutionary trees.

\section{Diagrammatic perspective}

While teaching tree-reading, educators should be cautious about the evolutionary trees they select to present to their learners. As mentioned before, numerous properties of evolutionary trees may hinder learning how to read them, and simultaneously, they might foster teleological interpretations. Therefore, a crucial step in planning a teaching unit about evolutionary trees is to decide which diagrams to use, how to improve them, and how to use different forms of diagrams.

\section{Tree design}

The most obvious distinctions between different evolutionary trees is the general type, or the outer shape of the diagram [rectangular, diagonal, or circular (see Fig. 2)], and the orientation of the diagram: where is the root and in which direction is the flow of time represented. Numerous studies show that evolutionary trees in a rectangular tree-format should be favored over diagonal trees as they are easier to read and are surrounded by a lower number of misconceptions (Crisp and Cook 2005; Meisel 2010; Novick and Catley 2007; Novick et al. 2010). In particular, diagonal trees seem to be prone to teleological interpretations because of the Gestalt principle of good continuation. Further, rectangular trees are more prevalent in scientific publications than the other formats (Novick and Catley 2007).

Besides the overall style of the tree, depictions of anagenetic developments can also influence the difficulty to read evolutionary trees and can reinforce teleological thinking (Catley and Novick 2008). Therefore, educators should question the extent to which anagenetic diagrams are suited for use in a learning context, the risk of reinforcing anagenetic interpretations, and the degree to which the potential consequences of reinforcing teleological interpretations can be compensated.

As students demonstrate less problematic interpretations and misconceptions when reading trees where extant organisms are presented along a horizontal line, i.e., where the flow of time is presented in the vertical direction, diagrams with this orientation should be preferred (Philips et al. 2011).

By carefully choosing the type of evolutionary tree to be used in which orientation, educators can greatly control the difficulty of tree-reading tasks. In modules on evolutionary trees, students should first be presented with trees in a rectangular form and should become acquainted with the other representational styles in the course of the module to familiarize them with the multitude of styles, and to prepare them to work with more difficult or misconception-loaded styles such as rectangular trees or anagenetic diagrams. Furthermore, complexityinducing properties of trees, such as the orientation of the tree, or the representation of species at differing levels, should be addressed at an appropriate time during the course of the unit, when students are familiar with the general concepts of how to read a tree.

\section{Tree properties}

In addition to the general form of the diagram, different properties need to be considered; for example, what further information can be presented with the diagram and how certain information is embedded in the diagram.

\section{Visualizing rotations}

It is advisable to present not only diagrams that have undergone a process of internal rotations, but to confront learners with multiple diagrams showing the same relationships. By learning that nodes can be rotated without altering the presented information, students can learn to better interpret trees as a nested hierarchy, including the concepts of sister groups (Meir et al. 2007; Philips et al. 2011). In order to visualize the possibility of rotating a 
tree without altering its content, one can lay cards representing species according to their relationship based on genetic data or traits (Gibson and Cooper 2017; Goldsmith 2003). Another approach can be to create threedimensional trees models that can be easily be modified, such as a mobile (Baum and Offner 2008) or built out of modifiable materials like pipe-cleaners (Halverson 2010). By pointing out that branches can be rotated around any node without altering the branching pattern or the relative relationship of the presented species, learners can see that the order in which species are presented in a diagram does not bear any deeper denotation, which is a basis for multiple misconceptions. This could lead to fewer interpretations addressing the complexity idea and misconceptions such as reading across the tips, which are linked to teleological reasoning (Baum and Offner 2008; Novick et al. 2014). Consequently, this should lead to fewer teleological-based interpretations. Besides reducing misconceptions, addressing rotations could lead students to gain a better understanding of how to interpret unbalanced trees and focal taxa.

\section{Positioning of focal taxa}

An important point is to think about the focal taxon in a tree diagram. Many evolutionary trees in the educational literature are used to present the relationship of one or a few groups of organisms in relation to other groups, the group or taxon under focus is called the focal taxon. In order to not substantiate interpretations based on a "special nature" of the focal taxon, this group should not be presented at one of the outmost positions in a given tree, as this could support the notion that this group is "more" developed than other groups (Novick et al. 2014).

As human thinking is prone to be anthropocentric (Kattmann 2008), we tend to put special focus on humans, or the presented taxonomic group containing humans (e.g., mammals or vertebrates) (Sandvik 2009). If humans are presented at a prominent position in an evolutionary tree, the anthropocentric view can be further supported. Similar interpretations can of course be seen if another group is the focal taxon, depending on the context of the representation. By rotating nodes inside the tree, humans can be presented at a location that is not expected by novice learners, and thus, it can possibly stimulate them into reflecting and questioning their own expectations (González Galli and Meinardi 2011; Meisel 2010; Novick et al. 2014; Philips et al. 2011). Educators should therefore desist from using trees where the focal taxon is presented at the outermost position in the tree. As many trees in educational literature especially present humans in such special positions and it might be difficult to avoid these diagrams completely, one should attempt to present a mix of diagrams where focal taxa are presented in prominent positions, as well as diagrams where the nodes have been rotated. By this, the concept that the order of taxa in a tree bears a deeper meaning instead of the underlying branching pattern might be contested.

\section{Adding additional information}

There exist some hints on how adding information to a diagram can ease the reading process of evolutionary trees. Although these actions have not been shown to decrease teleological thinking, they seem to decrease the occurrence of misconceptions related to teleological thinking. As many students frequently misinterpret the relative flow of time in a given tree (Gregory 2008; Meir et al. 2007; Omland 2014), it can be advisable to use trees showing at least an arrow indicating the direction of the flow of time, and even better, using a time axis along the diagram. The graphical representation of time helps student understanding of the course of evolutionary change and the order in which apomorphies or branching events took place. Furthermore, it can reduce the tendency of students to evaluate evolutionary relationships using the idea of "reading across the tips," assuming that species are presented in the tree in an ascending order of complexity and direct relationship (Baum and Offner 2008; Novick et al. 2014).

Evolutionary trees showing apomorphies along the branches of the tree are known to be easier to read and interpret than trees lacking this information. By adding apomorphies, the branching pattern of the tree and its nested hierarchy is better represented graphically. In particular, for the case of diagonal trees, apomorphies can help students extracting the correct structure by breaking the Gestalt principle of good continuation and breaking the tree down into smaller graphical parts (Novick et al. 2010).

Another way of adding helpful information to an evolutionary tree is to transform it to an "evogram", by bringing together multiple lines of evidence for the relative relationship of the presented species (Mead 2009; Padian 2008). In addition to the branching pattern, such a representation could incorporate apomorphies, graphical representations of genetic sequences, fossil evidence, as well as graphical elements showing morphological structures of the presented species (Padian 2008). Using an evogram can show students a broader picture of the evidence for the presented taxonomy and thus ease understanding of it. By making a diagram more comprehensible and conclusive, students might be less likely to turn to (teleological) misconceptions while interpreting it. 


\section{Instructional perspective}

A multitude of ways or actions can reduce the likelihood of students following teleological interpretations in a learning environment about evolutionary trees. Which of these ideas can be combined or are best suited in a situation depends a lot on the knowledge and ideas of the learners, the teaching style of the educator, circumstances of the learning environment, such as size of the learning group, available time, and numerous other factors. The following passage suggests some ideas that educators can use in their teaching methods to reduce the appeal of teleological thinking in tree-reading and facilitate student learning in the context of evolutionary trees.

\section{Start with families}

A possible way to embark on the field of reading evolutionary trees is by using family pedigrees to familiarize students with the concept of relative relationships, most recent common ancestors, and the way they can be depicted. By reducing the tree to one sex of the ancestors, for example the maternal line with respect to the heredity of mitochondria, the typical style of evolutionary trees is obtained. This allows students to use their knowledge of relationships and heredity on a familial level to develop an understanding of representations of relatedness (Baum and Offner 2008; Baum and Smith 2013; Baum et al. 2005; Meisel 2010). Instructors could advance from this start by zooming out from the family tree, showing how the pedigree fits into a tree of the population, and how this population fits into a species tree (Baum and Offner 2008; Baum and Smith 2013; Meisel 2010). While looking at family pedigrees allows novice learners to obtain an intuitive grasp of relative relationships using their everyday experiences, they need to understand that evolutionary trees are not the same as pedigrees. In particular, species have one ancestor whereas in a pedigree there are two. Furthermore, in an evolutionary tree, all represented species typically stem from one early ancestor and no groups are added along the time, as in a pedigree. Educators should be aware that the displays of pedigrees and evolutionary trees are different from one another, and these differences should be emphasized in order to avoid the development of new misconceptions (Meisel 2010).

\section{Start with circle-in-circle-diagrams}

Another way of introducing tree-reading is by using circle-in-circle-diagrams (see Fig. 4). These diagrams rely on depicting evolutionary relatedness using nested circles, representing different levels of relationship (Baum and Smith 2013; Jördens et al. 2012). Thus, students can easily get an understanding of the concept that a tree is a nested

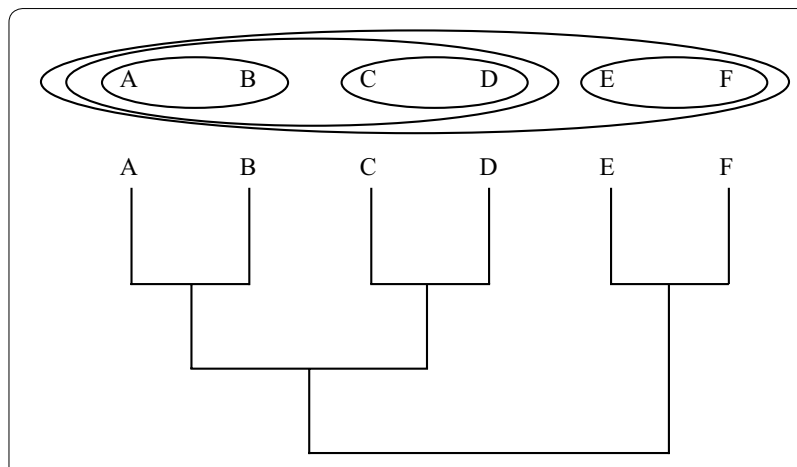

Fig. 4 A circle-in-circle diagram of six species and a corresponding rectangular tree diagram

hierarchy and that a branching event always results in sister groups, which are equally related to each other. Using this type of diagram allows students to easily grasp how taxonomic groups are organized (Catley et al. 2005; Jördens et al. 2012; Meisel 2010).

Circle-in-circle diagrams can be used to organize familiar groups intuitively and give students an easy introduction to constructing phylogenetic hypotheses. Card-sorting tasks (e.g., Gibson and Cooper 2017), where students organize species based on morphological or genetic data, may be used to structure relative relationships of the sorted species by nesting them in circles prior to constructing tree diagrams.

\section{Convert topologies}

In order to understand that different tree styles bear the same information and that the branching pattern, or topology, of a tree is the most important informational aspect, it can be advisable to get students to convert trees from one style into another (Baum and Smith 2013). By converting an evolutionary tree from, for example, the diagonal to a rectangular style, learners can better understand the aspects of both designs and get acquainted with the basic procedures in tree construction. Furthermore, they can understand the parts of the tree that correspond with each other and therefore contain the most meaning (Baum and Smith 2013). A better understanding of the tree styles being equivalent may reduce the risk of superficial or teleological interpretations, especially in the context of styles or orientations, which are prone to misinterpretations (see above).

\section{Consider the wording}

Students might not be aware of the problem teleological metaphors can pose in learning about evolution, especially because professional biologists and textbooks regularly use teleological wording. In order to address the issue in evolutionary education directly, students need 
to be made aware of their thinking processes (González Galli and Meinardi 2011; Trommler et al. 2018). The difficulty is that these thought processes typically occur implicitly, and they need to be made explicit by explaining one's own way of thinking. By engaging students to explain their rationale, teleological formulations will most likely arise. By picking these formulations up and using them in a constructive way of discussing how they conflict with biological models, rather than simply mark them as wrong, students should be made aware of the problem of teleology directly. For example, discussions can engage with the question of whether the statement was intended figuratively or literally and point out the limitations of everyday language in scientific contexts (González Galli and Meinardi 2011). In advanced classes, teleology could be picked up as a topic by analyzing different statements, both scientific and teleological, about evolution, working out the differences and potential problems and rephrasing teleological explanations or by making students aware of the metaphorical nature of many teleological wordings (González Galli and Meinardi 2011; Zohar and Ginossar 1998). This way teleological statements can be used to gain a deeper understanding of how to think about evolutionary processes (González Galli and Meinardi 2011; Zohar and Ginossar 1998; Kattmann 2008).

An issue with reacting to teleological statements is that students might not actually think teleologically, despite phrasing their statements this way. This can be because teleological statements are perceived as being less complicated and easier than scientifically valid statements (Talanquer 2013). As students might choose teleological wording although they do not hold the teleological idea, diagnosing teleological thinking cannot solely rely on finding teleological wordings, and it requires explicit questions regarding the underlying believes; the mere use of teleological language does not seem to be sufficient to actually account for teleological thinking (Coley and Tanner 2015). Therefore banning teleological language from biology education is not purposeful, as this ban does not necessarily lead to students changing their mindset (Zohar and Ginossar 1998). A difficulty in this regard is that the evolutionary discourse is characterized by the use of many ambiguous terms. Many students use terms like pressure or adapt in a non-scientific way, especially when showing a weaker overall academic performance (Rector et al. 2013).

\section{Address teleology}

A possible way of how to provide students with an opportunity to show their teleological mindset is to ask them to explain how evolutionary processes occur and what information evolutionary trees contain. Using information like a fossil record or evolutionary tree as a basis, asking students questions like "How and why did Species $\mathrm{X}$ develop?" or "How and why did trait Y develop?" can lay open students' potential teleological biases and thus stimulate a discussion about how to interpret evolutionary processes and representations (González Galli and Meinardi 2011; Werth 2012).

In the later part of a learning period, the educator could test in how far students changed their interpretations of evolutionary processes and representations from teleological to scientific reasoning by not asking simple questions of how a certain species or trait developed, but by posing questions that challenge the students' reasoning (González Galli and Meinardi 2011). These challenging questions could be about concepts such as the loss of function, lateral gene-transfer, or polytomies in an evolutionary tree, or a context, which is likely to conflict with the students' prior knowledge, such as the closer relative relationship of crocodiles to birds, rather than lizards (Baum and Offner 2008).

By making learners aware of the conceptual difficulties of teleology, especially in the context of evolution, they can be sensitized to problematic wording or representations, especially in a non-scientific or pop-cultural context. Misconceptions directly linked to teleological reasoning, such as misinterpreting the age of groups or the position of focal taxa might be reduced if students are familiar with the conceptual difficulties of teleological interpretations.

Educators can choose many practices to counter teleological reasoning in their learning environments (see Table 1). By critically reflecting and possibly altering the representations used, typical pitfalls and misconceptions will be less common. Furthermore, different instructional practices can affect teleological tendencies, ranging from the way the unit about phylogenetics commences, to concrete practices with evolutionary trees, or general aspects relating to language use.

\section{Conclusion and implications}

Given widespread misunderstandings and low levels of acceptance, educators need to be aware about the ways in which they are teaching evolution. Many factors influence the ways in which students perceive evolution; two very important ones are teleological thinking and the use of evolutionary trees.

Teleological thinking is a central difficulty in teaching and learning evolutionary biology. Students and educators on all educational levels tend to use teleological formulations and teleological interpretations of evolutionary processes. In particular, novice learners may face difficulties in understanding and applying evolutionary theory in complex biological problems. As a part of evolutionary biology, the field of using and 
Table 1 Overview of the reported misconceptions linked to teleological thinking and potential ways of confronting them

\begin{tabular}{|c|c|}
\hline $\begin{array}{l}\text { Misconception or educational } \\
\text { pitfall }\end{array}$ & Possible measures/practices \\
\hline Pop-cultural portrayal & $\begin{array}{l}\text { Tree design } \\
\text { Address teleology }\end{array}$ \\
\hline Reading across the tips & $\begin{array}{l}\text { Tree design } \\
\text { Visualize rotations } \\
\text { Adding additional information } \\
\text { Convert topologies }\end{array}$ \\
\hline Order of teaching evolution & $\begin{array}{l}\text { Start with families } \\
\text { Start with circle in circle diagrams }\end{array}$ \\
\hline Teleological wording & $\begin{array}{l}\text { Consider the wording } \\
\text { Illustrate and address teleology }\end{array}$ \\
\hline $\begin{array}{l}\text { Effects of different representational } \\
\text { styles }\end{array}$ & $\begin{array}{l}\text { Tree design } \\
\text { Visualize rotations } \\
\text { Convert topologies } \\
\text { Adding additional information }\end{array}$ \\
\hline Diagonal trees & $\begin{array}{l}\text { Tree design } \\
\text { Adding additional information } \\
\text { Convert topologies }\end{array}$ \\
\hline Anagenetic diagrams & Tree design \\
\hline Orientation of trees & $\begin{array}{l}\text { Tree design } \\
\text { Visualize rotations } \\
\text { Convert topologies }\end{array}$ \\
\hline Lines represent no change & Adding additional information \\
\hline Unbalanced trees & $\begin{array}{l}\text { Visualize rotations } \\
\text { Adding additional information }\end{array}$ \\
\hline Age of groups & $\begin{array}{l}\text { Address teleology } \\
\text { Visualize rotations }\end{array}$ \\
\hline Interpreting focal taxa & $\begin{array}{l}\text { Positioning of focal taxon } \\
\text { Address teleology } \\
\text { Consider the wording }\end{array}$ \\
\hline Different levels & Tree design \\
\hline
\end{tabular}

interpreting evolutionary trees as the central diagrammatic depiction of macro-evolutionary processes is far from being immune to these teleological pitfalls. Treereading is of major importance to understanding evolutionary biology; however, students from high-school to the post-secondary education face great difficulties and have a high number of persistent misconceptions about reading evolutionary trees. Thus, educators need to be aware of approaches that they can employ to minimize student use of teleological reasoning.

This work lays out several known and documented pitfalls in working with evolutionary trees in order to inform educators about the parts of teaching tree-reading that are susceptible to being influenced by and for promoting teleological misconceptions. The major teleological misconception in the field of reading evolutionary trees is the notion that different species can be classified as "higher" or "lower" (more or less "advanced"). Different teaching practices and various properties of evolutionary trees can promote this problematic idea in learners.
Besides presenting known teleological pitfalls, we provided educators with several approaches for how to confront and address teleological reasoning and thinking in their learning environments when working with evolutionary trees. Here, the approaches can be split into practices regarding the construction and design of tree diagrams and instructional approaches regarding general teaching practices.

This work contributes to the field of evolution education by helping educators identify teaching practices and properties of evolutionary trees that can unintentionally promote teleological thinking and reasoning. By countering teleological reasoning and making students aware of the difference between teleological and causal explanations, a deeper understanding of evolution can be achieved. If an increasing number of students attain a deeper understanding of evolution, its general acceptance might increase, and this may simultaneously result in less creationist views.

\section{Limitations}

The issue of teleological reasoning in the context of evolutionary education has often been addressed in recent years and, as in this work, has typically been seen as a hurdle in learning processes. Just as in many other circumstances, one should adopt a more nuanced perspective. Teleological interpretations are typically basal, non-scientific explanations for processes in the natural world, and they can be used as a gateway to more elaborate explanations. By making students aware of the metaphorical nature of their teleological statements, they can learn to critically reflect the metaphorical nature and possibly attain a deeper understanding of the evolutionary concepts (Kattmann 2008).

Few studies have explored the connections among teleological mindsets, evolution in general, and tree-reading. There seem to be some aspects, like different design elements of evolutionary trees, that encourage students to make teleological interpretations. Then again, a general teleological mindset might lead to faulty interpretations of evolutionary trees. Teleological mindsets, tree design and fragmentary knowledge about evolution could interact and lead to the emergence of teleological interpretations in different contexts of evolution. So, further research-especially experimental research approachesis needed to clarify these relations.

In the context of this work, we presented several pitfalls in teaching how to read evolutionary trees and subsequently, the different ways of avoiding them. Although several connections between pitfalls and teaching practices have been conducted, several implications presented are based on theoretical conclusions, and they have not been tested empirically. Further work testing these claims is needed. 


\section{Authors' contributions}

TS reviewed the literature, devised the line of thought and wrote the manuscript with support from PS. PS supervised the project and contributed to the manuscript. Both authors read and approved the final manuscript.

\section{Funding}

This project is funded by the German Federal Ministry of Education and Research under Grant Number 01PL16075.

Additional funding was provided by the Interdisciplinary Centre for Educational Research (IZfB) of the University Duisburg-Essen for professional language editing services and by the Open Access Publication Fund of the University of Duisburg-Essen for publication fees.

The responsibilities for the content of this publication lie with the authors.

\section{Availability of data and materials}

The datasets supporting the conclusions of this article are included within the article.

\section{Competing interests}

The authors declare that they have no competing interests.

Received: 24 September 2019 Accepted: 13 November 2019 Published online: 29 November 2019

\section{References}

Abrams E, Southerland S. The how's and why's of biological change: how learners neglect physical mechanisms in their search for meaning. Int J Sci Educ. 2001;23(12):1271-81. https://doi.org/10.1080/09500690110038558.

Ariew A. Ernst Mayr's 'ultimate/proximate' distinction reconsidered and reconstructed. Biol Philos. 2003;18(4):553-65.

Barnes ME, Evans EM, Hazel A, Brownell SE, Nesse RM. Teleological reasoning, not acceptance of evolution, impacts students' ability to learn natural selection. Evol Edu Outreach. 2017;10(1):152. https://doi.org/10.1186/ s12052-017-0070-6.

Baum DA, Offner S. Phylogenics and tree-thinking. Am Biol Teach. 2008;70(4):222-9.

Baum DA, Smith SD. Tree thinking: an introduction to phylogenetic biology. Greenwood Village Col.: Roberts; 2013.

Baum DA, Smith SD, Donovan SSS. Evolution. The tree-thinking challenge. Science. 2005;310(5750):979-80. https://doi.org/10.1126/science.1117727.

Blacquiere LD, Hoese WJ. A valid assessment of students' skill in determining relationships on evolutionary trees. Evol Edu Outreach. 2016;9(1):979. https://doi.org/10.1186/s12052-016-0056-9.

Bokor JR, Landis JB, Crippen KJ. High school students' learning and perceptions of phylogenetics of flowering plants. CBE Life Sci Educ. 2014;13(4):65365. https://doi.org/10.1187/cbe.14-04-0074.

Borgerding LA, Deniz H. Evolution education around the globe: conclusions and future directions. In: Deniz H, Borgerding LA, editors. Evolution education around the globe. Cham: Springer; 2018. p. 449-64. https:// doi.org/10.1007/978-3-319-90939-4_24.

Campbell A. Evolution education in New Zealand. In: Deniz H, Borgerding LA, editors. Evolution education around the globe. Cham: Springer; 2018. p. 431-46. https://doi.org/10.1007/978-3-319-90939-4_23.

Catley KM, Lehrer R, Reiser B. Tracing a prospective learning progression for developing understanding of evolution. In: Paper commissioned by the national academics committee on test design for K-12 science achievement. Washington, DC: National Academy of Sciences; 2005.

Catley KM, Novick LR. Seeing the wood for the trees: an analysis of evolutionary diagrams in biology textbooks. Bioscience. 2008;58(10):976. https:// doi.org/10.1641/B581011.

Catley KM, Novick LR, Shade CK. Interpreting evolutionary diagrams: when topology and process conflict. J Res Sci Teach. 2010;47(7):861-82. https:// doi.org/10.1002/tea.20384.

Catley KM, Novick LR, Funk D. The promise and challenges of introducing tree thinking into evolution education. In: Rosengren KS, Brem SK, Evans EM, editors. Evolution challenges: integrating research and practice in teaching and learning about evolution. Oxford: Oxford University Press; 2012. p. 93-101.

Clark CA. "You are here": missing links, chains of being, and the language of cartoons. Isis. 2009;100(3):571-89.
Coley JD, Tanner K. Relations between intuitive biological thinking and biological misconceptions in biology majors and nonmajors. CBE Life Sci Educ. 2015;14(1):ar8. https://doi.org/10.1187/cbe.14-06-0094.

Crisp MD, Cook LG. Do early branching lineages signify ancestral traits? Trends Ecol Evol. 2005;20(3):122-8. https://doi.org/10.1016/j.tree.2004.11.010

Cunningham DL, Wescott DJ. Still more "Fancy" and "Myth" than "Fact" in Students' conceptions of evolution. Evo Edu Outreach. 2009;2(3):505-17. https://doi.org/10.1007/s12052-009-0123-6.

Darwin C. On the origin of species by means of natural selection, or the preservation of favoured races in the struggle for life. London: Murray; 1859.

Dees J, Momsen JL, Niemi J, Montplaisir L. Student interpretations of phylogenetic trees in an introductory biology course. CBE Life Sci Educ. 2014;13(4):666-76. https://doi.org/10.1187/cbe.14-01-0003.

Deniz H, Borgerding LA. Evolutionary theory as a controversial topic in science curriculum around the globe. In: Deniz H, Borgerding LA, editors. Evolution education around the globe. Cham: Springer; 2018. p. 3-11. https:// doi.org/10.1007/978-3-319-90939-4_1.

Dobzhansky T. Nothing in biology makes sense except in the light of evolution. Am Biol Teach. 1973;35(3):125-9.

Evans EM. Cognitive and contextual factors in the emergence of diverse belief systems: creation versus evolution. Cogn Psychol. 2001;42(3):217-66. https://doi.org/10.1006/cogp.2001.0749.

Friedrichsen PJ, Brown LG, Schul J. Project teach evolution: preparing biology pre-service teachers to teach evolution in Missouri, USA. In: Deniz H, Borgerding $L A$, editors. Evolution education around the globe. Cham: Springer; 2018. p. 41-58. https://doi.org/10.1007/978-3-319-90939-4_3.

Futuyma DJ. Evolution. 3rd ed. Sunderland: Sinauer Associates; 2013.

Gibson JP, Cooper JT. Botanical phylo-cards: a tree-thinking game to teach plant evolution. Am Biol Teach. 2017;79(3):241-4. https://doi.org/10.1525/ abt.2017.79.3.241.

Goldsmith DW. The great clade race. Am Biol Teach. 2003;65(9):679-82.

González Galli LM, Meinardi EN. The role of teleological thinking in learning the Darwinian model of evolution. Evo Edu Outreach. 2011;4(1):145-52. https://doi.org/10.1007/s12052-010-0272-7.

Gould SJ. Ladders and cones: constraining evolution by canonical icons. In: Silvers RB, editor. Hidden histories of science. 1st ed. New York: Review of Books; 1995. p. 37-68.

Gould SJ. Full house: the spread of excellence from Plato to Darwin. New York: Harmony; 1996.

Gregory TR. Understanding evolutionary trees. Evo Edu Outreach. 2008;1(2):121-37. https://doi.org/10.1007/s12052-008-0035-X.

Gregory TR. Understanding natural selection: essential concepts and common misconceptions. Evo Edu Outreach. 2009;2(2):156-75. https://doi. org/10.1007/s12052-009-0128-1.

Gregory TR, Ellis CAJ. Conceptions of evolution among science graduate students. Bioscience. 2009;59(9):792-9. https://doi.org/10.1525/ bio.2009.59.9.10

Halverson KL. Using pipe cleaners to bring the tree of life to life. Am Biol Teach. 2010;72(4):223-4. https://doi.org/10.1525/abt.2010.72.4.4.

Halverson KL. Improving tree-thinking one learnable skill at a time. Evo Edu Outreach. 2011;4(1):95-106. https://doi.org/10.1007/s12052-010-0307-0.

Halverson KL, Friedrichsen P. Learning tree thinking: developing a new framework of representational competence. In: Treagust DF, Tsui C-Y, editors. Multiple representations in biological education. Dordrecht: Springer; 2013. p. 185-201. https://doi.org/10.1007/978-94-007-4192-8_11.

Hanke D. Teleology: the explanation that bedevils biology. In: Cornwell J, editor. Explanations: styles of explanation in science. Oxford: OUP Oxford: 2004. p. 143-55.

Jördens J, Asshoff R, Kullmann H. Stammbäume lesen und verstehen. In: Dreesmann DC, Graf D, Witte K, editors. Evolutionsbiologie: moderne Themen für den Unterricht. Heidelberg: Springer; 2012. p. 377-403.

Kampourakis K. Understanding evolution. Cambridge: Cambridge University Press; 2014

Kampourakis K, Zogza V. Students' preconceptions about evolution: how accurate is the characterization as "Lamarckian" when considering the history of evolutionary thought? Sci Educ. 2007;16(3-5):393-422. https:// doi.org/10.1007/s11191-006-9019-9.

Kattmann U. Learning biology by means of anthropomorphic conceptions. In: Hammann M, Reiss M, Boulter C, Dale Tunnicliffe S, Hume Keynes R, Kattmann $U$, et al., editors. Biology in context: learning and teaching for the twenty-first century. London: Institute of Education Press; 2008. p. 7-17. 
Keil FC. The growth of causal understandings of natural kinds. In: Sperber D, editor. Causal cognition: a multidisciplinary debate; a Fyssen Foundation symposium. 1st ed. Oxford: Clarendon Press; 2002. p. 234-62. https://doi. org/10.1093/acprof:oso/9780198524021.003.0009.

Kelemen D. Function, goals and intention: children's teleological reasoning about objects. Trends Cogn Sci. 1999a;3(12):461-8. https://doi.org/10.1016/S1364 $-6613(99) 01402-3$

Kelemen D. The scope of teleological thinking in preschool children. Cognition. 1999b;70(3):241-72. https://doi.org/10.1016/S0010-0277(99)00010-4.

Kelemen D. Why are rocks pointy? Children's preference for teleological explanations of the natural world. Dev Psychol. 1999c;35(6):1440-52. https://doi. org/10.1037/0012-1649.35.6.1440.

Kelemen D. Teleological minds: how natural intuitions about agency and purpose influence learning about evolution. In: Rosengren KS, Brem SK, Evans EM, editors. Evolution challenges: integrating research and practice in teaching and learning about evolution. Oxford: Oxford University Press; 2012. p. 66-92.

Kelemen D, Rosset E. The human function compunction: teleological explanation in adults. Cognition. 2009;111(1):138-43. https://doi.org/10.1016/j.cogni tion.2009.01.001.

Kummer TA, Whipple CJ, Jensen JL. Prevalence and persistence of misconceptions in tree thinking. J Microbiol Biol Educ. 2016;17(3):389-98. https://doi. org/10.1128/jmbe.v17i3.1156.

Lay YF, Ong ET, Han CGK, Chan SH. A glimpse of evolution education in the Malaysian context. In: Deniz H, Borgerding LA, editors. Evolution education around the globe. Cham: Springer; 2018. p. 357-74. https://doi. org/10.1007/978-3-319-90939-4_19.

MacDonald T, Wiley EO. Communicating phylogeny: evolutionary tree diagrams in museums. Evo Edu Outreach. 2012;5(1):14-28. https://doi.org/10.1007/ s12052-012-0387-0.

Matuk C. Images of evolution. J Biocommun. 2007;33(3):E54-61.

Mead LS. Transforming our thinking about transitional forms. Evo Edu Outreach. 2009;2(2):310-4. https://doi.org/10.1007/s12052-009-0126-3.

Mead LS, Scott EC. Problem concepts in evolution part I: purpose and design. Evo Edu Outreach. 2010a;3(1):78-81. https://doi.org/10.1007/s1205 2-010-0210-8.

Mead LS, Scott EC. Problem concepts in evolution part II: cause and chance. Evo Edu Outreach. 2010b;3(2):261-4. https://doi.org/10.1007/s1205 2-010-0231-3.

Meir E, Perry J, Herron JC, Kingsolver J. College students' misconceptions about evolutionary trees. Am Biol Teach. 2007;69(7):e71-6.

Meisel RP. Teaching tree-thinking to undergraduate biology students. Evolution. 2010;3(4):621-8. https://doi.org/10.1007/s12052-010-0254-9.

Mogie M. Historical baggage in biology: the case of 'higher' and 'lower'species. BioEssays. 2000;22(9):868-9.

Nee S. The great chain of being. Nature. 2005;435(7041):429. https://doi. org/10.1038/435429a.

Nehm RH, Kampourakis K. History and philosophy of science and the teaching of macroevolution. In: Matthews MR, editor. International handbook of research in history, philosophy and science teaching. Dordrecht: Springer; 2014. p. 401-21. https://doi.org/10.1007/978-94-007-7654-8_14.

Nehm RH, Schonfeld IS. Does increasing biology teacher knowledge of evolution and the nature of science lead to greater preference for the teaching of evolution in schools? J Sci Teach Educ. 2007;18(5):699-723. https://doi. org/10.1007/s10972-007-9062-7.

Nehm RH, Schonfeld IS. Measuring knowledge of natural selection: a comparison of the CINS, an open-response instrument, and an oral interview. J Res Sci Teach. 2008;45(10):1131-60. https://doi.org/10.1002/tea.20251.

Novick LR, Catley KM. Understanding phylogenies in biology: the influence of a Gestalt Perceptual Principle. J Exp Psychol Appl. 2007;13(4):197-223. https:// doi.org/10.1037/1076-898X.13.4.197.

Novick LR, Catley KM. When relationships depicted diagrammatically conflict with prior knowledge: an investigation of students' interpretations of evolutionary trees. Sci Educ. 2014;98(2):269-304. https://doi.org/10.1002/ sce.21097.

Novick LR, Catley KM. Fostering 21st-century evolutionary reasoning: teaching tree thinking to introductory biology students. CBE Life Sci Educ. 2016. https://doi.org/10.1187/cbe.15-06-0127.

Novick LR, Catley KM, Funk D. Characters are key: the effect of synapomorphies on cladogram comprehension. Evo Edu Outreach. 2010;3(4):539-47. https ://doi.org/10.1007/s12052-010-0243-z.
Novick LR, Pickering J, MacDonald T, Diamond J, Ainsworth S, Aquino AE, et al. Depicting the tree of life in museums: guiding principles from psychological research. Evo Edu Outreach. 2014;7(1):669. https://doi. org/10.1186/s12052-014-0025-0.

O'Hara RJ. Population thinking and tree thinking in systematics. Zool Scripta. 1997;26(4):323-9. https://doi.org/10.1111/j.1463-6409.1997.tb00422.x.

Omland KE. Interpretation of phylogenetic trees. In: Losos JB, editor. The Princeton guide to evolution. Princeton: Princeton University Press; 2014. p. 51-9.

Omland KE, Cook LG, Crisp MD. Tree thinking for all biology: the problem with reading phylogenies as ladders of progress. BioEssays. 2008;30(9):854-67. https://doi.org/10.1002/bies.20794.

Padian K. Trickle-down evolution: an approach to getting major evolutionary adaptive changes into textbooks and curricula. Integr Comp Biol. 2008;48(2):175-88. https://doi.org/10.1093/icb/icn023.

Philips BC, Novick LR, Catley KM, Funk D. Interactive effects of Diagrammatic Format and Teleological Beliefs on Tree Thinking. In: Ohlsson S, Catrambone R, eds. 32nd Annual Meeting of the Cognitive Science Society 2010, Portland, Oregon, USA, 11-14 August 2010. Red Hook, NY: Curran Associates Inc; 2011. p. 2656-2661.

Pietsch TW. Trees of life: a visual history of evolution. Baltimore: Johns Hopkins University Press; 2012.

Quessada M-P, Clément P. Evolution education in france: evolution is widely taught and accepted. In: Deniz H, Borgerding LA, editors. Evolution education around the globe. Cham: Springer; 2018. p. 213-33. https://doi. org/10.1007/978-3-319-90939-4_12.

Rector MA, Nehm RH, Pearl D. Learning the language of evolution: lexical ambiguity and word meaning in student explanations. Res Sci Educ. 2013;43(3):1107-33. https://doi.org/10.1007/s11165-012-9296-z.

Reiss MJ. Creationism and intelligent design. In: Smeyers P, editor. International handbook of philosophy of education. Cham: Springer; 2018. p. 1247-59. https://doi.org/10.1007/978-3-319-72761-5_86.

Rosenberg A, McShea DW. Philosophy of biology: a contemporary introduction. New York: Routledge; 2008.

Ruse M. Evolutionary biology and teleological thinking. In: Ariew A, Cummins R, Perlman M, editors. Functions: new essays in the philosophy of psychology and biology. Oxford: Oxford University Press; 2009. p. 33-60.

Sandvik H. Anthropocentricisms in cladograms. Biol Philos. 2009;24(4):425-40. https://doi.org/10.1007/s10539-007-9102-x.

Schramm T, Schachtschneider Y, Schmiemann P. Understanding the tree of life: an overview of tree-reading skill frameworks. Evo Edu Outreach. 2019;12(1):1538. https://doi.org/10.1186/s12052-019-0104-3.

Scott M. The pleasures and pitfalls of teaching human evolution in the museum. Evo Edu Outreach. 2010;3(3):403-9. https://doi.org/10.1007/s1205 2-010-0252-y.

Southerland SA, Abrams E, Cummins CL, Anzelmo J. Understanding students' explanations of biological phenomena: conceptual frameworks or p-prims? Sci Educ. 2001;85(4):328-48. https://doi.org/10.1002/sce.1013.

Talanquer V. When atoms want. J Chem Educ. 2013;90(11):1419-24. https://doi. org/10.1021/ed400311x.

Tamir P, Zohar A. Anthropomorphism and teleology in reasoning about biological phenomena. Sci Educ. 1991;75(1):57-67. https://doi.org/10.1002/sce.37307 50106.

Taylor MR, Simon EJ, Dickey JL, Hogan KA, Reece JB, Campbell NA. Campbell biology: concepts AND connections. New York: Pearson Education, Inc; 2018.

Trommler F, Gresch H, Hammann M. Students' reasons for preferring teleological explanations. Int J Sci Educ. 2018;40(2):159-87. https://doi. org/10.1080/09500693.2017.1404658.

Werth A. Avoiding the pitfall of progress and associated perils of evolutionary education. Evo Edu Outreach. 2012;5(2):249-65. https://doi.org/10.1007/ s12052-012-0417-y.

Wiley J, Sarmento D, Griffin TD, Hinze SR. Biology textbook graphics and their impact on expectations of understanding. Discourse Process. 2017;12:1-16. https://doi.org/10.1080/0163853X.2017.1319655.

Zohar A, Ginossar S. Lifting the taboo regarding teleology and anthropomorphism in biology education?Heretical suggestions. Sci Educ. 1998;82(6):679-97.

\section{Publisher's Note}

Springer Nature remains neutral with regard to jurisdictional claims in published maps and institutional affiliations. 